\title{
Apuntes para la edición crítica de la obra de Diego López de Haro, poeta cancioneril
}

\author{
Lucila GONZÁLEZ ALFAYA \\ Universidad de Vigo \\ lucilaga@uvigo.es
}

\begin{abstract}
RESUMEN
Diego López de Haro es una figura relevante del último tercio del siglo XV; perteneciente a una de las familias nobles más importantes de la época, su vida está ligada a la Corte, en todos sus ámbitos, el político, el militar, el diplomático y, también, el literario. El Cancionero general recoge más de una treintena de obras del autor y deja constancia de su participación en justas poéticas cortesanas y de su influencia en otros autores cancioneriles. Esta somera presentación anticipa algunas de las dificultades que entraña la edición crítica de su obra poética, que es el objeto de mi tesis doctoral. En este artículo presentaré en qué consiste el trabajo que estoy llevando a cabo, por lo que trataré de contextualizar el autor y su obra, facilitando datos sobre la localización de su poesía, para a continuación detenerme en aspectos específicos relativos a la tarea de edición, prestando especial atención a la relación entre el Cancionero general (11CG) y el Cancionero de la British Library o Cancionero de Rennert (LB1).
\end{abstract}

Palabras clave: Diego López de Haro, poesía cancioneril, ecdótica.

\begin{abstract}
Diego López de Haro is a prominent figure in the last third of the fifteenth century; belonging to one of the most important noble families of the time, his life is bound up with the Court, in all fields, political, military, diplomatic and also literary. The Cancionero general includes more than thirty poems of the author and records his participation in courtly poetic tournaments as well as his influence on other cancionero authors. This brief presentation anticipates some of the difficulties involved in the preparation of the critical edition of his poetry, which is the subject of my doctoral thesis. In the following pages I will present the work I am developing, thus I will try first to contextualize the author and his work, by providing information on his poetry's location, and I will then dwell upon issues that relate specifically to the ecdotic work, paying particular attention to the relationship between the Cancionero general (11CG) and the Cancionero de la British Library or Cancionero de Rennert (LB1).
\end{abstract}

Keywords: Diego López de Haro, Cancionero Poetry, Textual Criticism. 
Tras un largo período en el que los estudios sobre poesía cancioneril castellana escaseaban, en las últimas décadas ha surgido un nuevo interés que puede observarse tanto en la celebración de congresos como en el creciente número de publicaciones sobre el tema. En este contexto, uno de los aspectos que ha merecido la atención de los investigadores ha sido la labor ecdótica, que ha dado como fruto bien ediciones de cancioneros completos, bien de la obra de un autor.

En esta línea se enmarca mi proyecto de tesis doctoral, que, desarrollada en la Universidad de Vigo, bajo la dirección del doctor Antonio Chas Aguión, tiene como objetivo ofrecer la edición crítica de la obra poética de Diego López de Haro, personaje destacado de la Castilla del último tercio del siglo $\mathrm{XV}^{1}$. En este artículo presentaré en qué consiste el trabajo que estoy llevando a cabo, por lo que trataré de contextualizar el autor y su obra, facilitando datos sobre la localización de su poesía en los cancioneros castellanos, para a continuación detenerme en aspectos específicos relativos a la tarea de edición, prestando especial atención a la relación entre dos importantes cancioneros, el Cancionero general y el Cancionero de la British Library o Cancionero de Rennert. Creo oportuno subrayar, por ello mismo, que el trabajo que aquí presento es parte de una investigación todavía en desarrollo ${ }^{2}$.

Hijo primogénito de Juan Alfonso de Haro y Aldonza de Mendoza, su linaje se relaciona con ilustres familias españolas (Ayala, Mendoza, Silva, Girón, Sotomayor, etc.) y ocupa un puesto destacado en el sistema señorial de la segunda mitad del siglo XV. Aunque no se conoce con exactitud la fecha de su nacimiento, Elena Elisabetta Marcello la sitúa entre 1438 y $1449^{3}$. Desde su juventud toma partido, junto a su padre, en distintos enfrentamientos y alianzas, lo que culmina con el "Cartel de desafío" que envía en 1480 a Pedro Fajardo, con quien se habían sucedido las muestras de enemistad a lo largo de los años; el duelo no llegó a celebrarse, puesto que los Reyes Católicos derogaron este privilegio nobiliar antes de que pudiesen hacerlo. Este hecho debió de dejar una profunda huella en el poeta, ya que en una carta dirigida al emperador Carlos $\mathrm{V}$, en la que a modo de memorial enumera las distintas virtudes que debe poseer un buen monarca, en el apartado dedicado a la Verdad indica: "paréceme que a seruiçio de Dios y de Vuestra Alteza convenía

\footnotetext{
${ }^{1}$ Cuento para ello con una beca predoctoral del programa de Recursos Humanos "María Barbeito", de la Xunta de Galicia.

${ }^{2}$ Este trabajo se inscribe en el proyecto de investigación "Autores y textos gallegos en la poesía castellana medieval” (código: INCITE09 104249 PR), financiado por la Xunta de Galicia.

${ }^{3}$ E. E. Marcello (1995), pp. 116-117.

${ }^{4}$ Erasmo Buceta, en la primera mitad del siglo XX, publicó varios trabajos relacionados con la vida y la obra del autor, entre los que se encuentra la edición de este "Cartel de desafío" (Buceta, 1933).
} 
que la ley de los rieptos y desafíos la mandase renouar, por ser esta ley descanso del rey y bondad de caualleros"5.

Pese a haber militado en el partido alfonsino ${ }^{6}$ y haber apoyado probablemente al bando favorable a Juana la Beltraneja, el poeta logra reconciliarse con los Reyes Católicos y emprender una brillante carrera como funcionario real. Así, tras haber adquirido varias alcaidías, con sus rentas y privilegios, en 1484 es nombrado gobernador del reino de Galicia, territorio que suponía en aquel momento un importante problema de política interna para los monarcas.

Ocupa este cargo durante más de una década y entre los hechos más destacados ocurridos en el transcurso de este tiempo se encuentra la visita de los Reyes Católicos a Santiago de Compostela en $1486^{7}$, año en el que los monarcas conceden una amnistía general para todos aquellos gallegos dispuestos a participar en la Guerra de Granada bajo las órdenes de López de Haro ${ }^{8}$. Los monarcas también le confían una importante tarea diplomática: en 1493 viaja a Italia como Embajador de Obediencia de los Reyes Católicos ante Alejando VI (Rodrigo Borja). Llega a Roma en junio de ese año escoltado, por orden papal, por el Duque de Gandía, por César Borja y por Giovanni Sforza, recién casado con Lucrecia Borja ${ }^{9}$.

$\mathrm{Su}$ actividad en la Corte se completa con su participación en círculos literarios y en justas poéticas. La obra del autor que se ha conservado no es muy extensa (comprende unos cuarenta textos), pero deja constancia de que su actividad poética no fue solo ocasional y debió de ser suficientemente conocida como para que otros autores lo citen como modelo y para entrar a formar parte de dos de los cancioneros más importantes de finales del siglo XV, el Cancionero general de Hernando del Castillo y el manuscrito Cancionero de la British Library.

El cancionero que Hernando del Castillo publica en Valencia en 1511, 11CG en la terminología de Dutton ya institucionalizada, recoge 29 de las 39 piezas que se conservan del poeta ${ }^{10}$, distribuidas en tres de sus secciones; en la "de amores" se agrupan trece composiciones del autor ${ }^{11}$, todas ellas de tema amoroso, excepto la

${ }^{5}$ E. Buceta (1930), p. 375.

${ }^{6}$ E. E. Marcello (1995), p. 118.

${ }^{7}$ López Ferreiro (1968), pp. 111-121.

${ }^{8}$ García Oro (1987), pp. 401-408.

${ }^{9}$ E. Buceta (1929b), p. 156.

${ }^{10}$ Para este cómputo no tengo en cuenta los versos que Garci Sánchez de Badajoz pone en boca de Diego López de Haro en su Infierno de amores (ID0662, "Caminando en las honduras"), a los que Brian Dutton consigna un número ID (ID0665), ni los tres poemas de paternidad discutida que LB1 atribuye a nuestro autor (ID1115, ID0779 y ID1125).

${ }^{11}$ Se trata de los siguientes poemas (enumero en el orden en el que aparecen en el cancionero): ID1121, "Pensamiento pues mostrays"; ID1122, "Carta pues que vas a ver"; ID1123, "Esta merced cerradura"; ID1113, "De vos me parto quexando"; ID6080, "O que no hallo razon"; ID6081, "Si el presto creer me culpa"; ID6082, "Veys aqui do bueluo yo"; ID6083, 
que abre el bloque, el "Diálogo entre la Razón y el Pensamiento" (ID1121, "Pensamiento pues mostrays"), un extenso poema alegórico en el que la Razón intenta convencer al Pensamiento de que abandone la senda del Amor y vuelva al camino de la Virtud.

Hernando del Castillo recoge seis canciones del poeta en la sección que dedica a este género, aunque dos de ellas son en realidad una misma, ID 6269, "Vista esta la perdicion", que aparece repetida ${ }^{12}$; no obstante, la autoría de Diego López de Haro queda consignada en ambos casos. Además, Pietro Bembo cita cinco versos de esta composición en una de las cartas enviadas a Lucrecia Borja que se conservan en un manuscrito (S.P.II.100) de la Biblioteca Ambrosiana de Milán (MI1) ${ }^{13}$, y también en este caso es clara la atribución a nuestro autor. Por último, en el apartado de "invenciones y letras de justadores" figuran once piezas suyas ${ }^{14}$, lo que lo convierte en el poeta mejor representado en esta sección del cancionero. Dada la naturaleza del género, este dato da cuenta de la participación activa del autor en los juegos poéticos cortesanos ${ }^{15}$.

"Yo soy el que siempre llora"; ID1118, "No lloro yo los dolores"; ID4140, "Despues que os vi entristecida"; ID1116, "Penoso esta el sentimiento"; ID6084, "Pues no me vale ventura" ; ID6085, "Ya no se como me quexe".

12 Son las siguientes ID1124, "Ved que tal es mi bevir"; ID6269, "Vista esta la perdicion"; ID1120, "Quando açierta el desear"; ID6298, "Si queres al mal que siento"; ID6299, "Por tal ocasion venida".

${ }^{13}$ G. Mazzocchi (1989).

14 A saber: ID0927, "Todas estas confirmaron"; ID0930, "Traygo esperança porque"; ID4146, "Quando de mi coraçon"; ID6362, "Curo partida por medio"; ID6363, "Es la rama ell esperança"; ID6366, "Quando el tal sin que se asombre"; ID0931, "Ved el bivo si es razon"; ID6367, "Lo que memoria possee"; ID6368, "Que todos pudieran ver"; ID0932, "Traygo como veys tristura"; ID6384, "Dun dolor que Dios os guarde".

${ }^{15} \mathrm{Si}$ bien este género fue tradicionalmente poco atendido por la crítica, hoy en día son numerosos los estudios que se centran en él, desde perspectivas muy distintas. Alan Deyermond, en su "Micropoética de las invenciones" (2002, p. 413) ofrece una panorámica sobre los primeros estudios sobre este género, partiendo del de Francisco Rico (1966), y destaca la repercusión que tuvieron los trabajos de Ian Macpherson (en particular su edición de las invenciones del Cancionero general, 1998), que llamaron la atención sobre la necesidad de incorporar la investigación histórica a la hora de abordar estos textos. De los trabajos sobre el género que se publican a partir de entonces, cabe destacar aquí el de María Luzdivina Cuesta (2000) y el de Kirstin Kennedy (2002): ambas editan las invenciones de Diego López de Haro, pero la primera parte de las recogidas en el Cancionero general, mientras que la segunda tiene en cuenta las que aparecen en el Cancionero de la British Library. En este sentido, hay que hacer referencia a la edición de las invenciones de LB1 realizada por John Gornall (2003a), así como a la ya citada de Ian Macpherson (1998) y a la sección dedicada a este género en el Cancionero general que se incluye en la edición llevada a cabo por Joaquín González Cuenca (2004). En la bibliografía final doy cuenta de otros trabajos relacionados con el género, pero que no atañen tan directamente a la obra de López de Haro. 
En 1514 se publica, también en Valencia, la segunda edición del Cancionero general (14CG), que el propio Hernando del Castillo se encarga de supervisar y corregir, realizando tanto supresiones como adiciones con respecto a 11CG. En el caso de López de Haro, se elimina una de las versiones de la canción que aparecía repetida (ID6269) y se añaden cuatro composiciones, de forma que pasa a tener representación en dos nuevas secciones. En la de "obras de devoción y moralidad" figura un villancico (ID6803, "Pues hijo de dios pari") que, puesto en boca de la propia María, defiende la Inmaculada Concepción. Otro villancico, en este caso de tema amoroso (ID6858, "Mi esperança es acabada"), se añade al apartado explícitamente dedicado a este género.

Las otras dos adiciones que afectan a $14 \mathrm{CG}$ son, por una parte, una canción (ID6831, "O desdichado desseo"), que se integra en la sección correspondiente, y, por otra, un texto con el que se cierra el bloque de poemas del autor en el apartado de "obras de amores", el "Testamento de amores" (ID1114, "O muy alto dios de amor"). Lo que resulta llamativo de este poema, sin embargo, es su ausencia en la primera edición del Cancionero general, puesto que se trata de una obra compuesta sin duda antes de que Hernando del Castillo llevase por primera vez a las prensas su compilación y que debió de ser ampliamente conocida. Prueba de ello es que Garci Sánchez de Badajoz lo cita como modelo a seguir en su propio "Testamento" (ID1769, "Pues amor quiere que muera"), que sí figura entre las páginas de 11CG:

\section{Pero que lleve, declaro, la misma forma y tenor aquel que hizo de Amor don Diego López de Haro, pues yo muero amador ${ }^{16}$}

Esta no es la única obra de Garci Sánchez en la que alude a López de Haro, pues en su "Infierno de amor" (ID0662, "Caminando en las honduras") se refiere a él como ejemplo de poeta enamorado, situándolo entre Juan de Mena y Jorge Manrique. Aunque no se conservan otras referencias directas de poetas cancioneriles a la obra de Diego López de Haro, las palabras de Garci Sánchez parecen indicar que se trataba de una figura reconocida en los círculos literarios, hecho que ya apuntaba el número de invenciones recogidas en el Cancionero general. Otra prueba de ello se encuentra en el Cacionero de Juan Álvarez Gato (MH4), en el que se recoge el único testimonio conservado de dos poemas del autor: ID3131, "En vuestra vida pensando", e ID3166, "Señor bien y mal esto". Francisco Márquez Villanueva, al estudiar la poesía de Álvarez Gato, veía en la rúbrica de una de las composiciones de nuestro autor (ID3131) indicios de una relación de amistad entre ambos poetas: "Don Diego Lopez de Haro, como vido a Juan Alvarez tan mudado de la cosas que

${ }^{16}$ C. Parrilla (2001), pp. 49-50. 
solíe conversar con él, juzgándolo a la mejor parte, como an de hazer los buenos, hizo esta copla, y aun porque él le dio parte de su entençion" $" 17$.

Como ya he señalado hace un instante, Diego López tiene también representación en otro importante cancionero de finales del siglo XV y principios del XVI, un manuscrito custodiado actualmente en la Biblioteca Británica (Ms. Add. 10431), conocido como Cancionero de la British Library o Cancionero de Rennert (o LB1 en las siglas de Brian Dutton), el cual comparte un gran número de composiciones con el Cancionero general, pero presenta también notables diferencias, desde ser manuscrito, hasta la organización y calidad de los materiales que recoge ${ }^{18}$. Son 19 las obras que en este códice se le atribuyen al autor: por una parte, entre un grupo de invenciones de distintos personajes, aparecen cuatro suyas ${ }^{19}$, que figuran también en el Cancionero general; por otra, se agrupan 15 piezas bajo el epígrafe "Coplas de don Diego López de Haro, y dizen de un descontentamiento que lleva por una partida que hizo de donde queda su amiga", 12 de atribución segura y las otras tres de paternidad discutida ${ }^{20}$. Ocho de las 12 de atribución segura las comparte con $11 \mathrm{CG}$, y una más con 14CG. Además, de una de las piezas que comparten el Cancionero general y el Cancionero de la British Library se conoce también otro testi-

\footnotetext{
${ }_{17}^{17}$ F. Márquez Villanueva (1960), p. 166.

${ }^{18} \mathrm{El}$ manuscrito ha sido estudiado desde distintos puntos de vista, tales como la autoría (R. O. Jones, 1961), la historia del códice (J. C. Conde, 2007) y, sobre todo, la datación y la relación con otros cancioneros (ambos aspectos fuertemente ligados), en especial con el de Hernando del Castillo. Ya su primer editor notó el elevado número de textos comunes entre ambos cancioneros, por lo que prescindió de todos aquellos incluidos en el Cancionero general (H. A. Rennert, 1899). Hoy en día los trabajos que se acercan al estudio de esta relación, más o menos directamente, son numerosos. Entre los más destacados se encuentran los de C. Alvar (1989), P. Botta (2002), B. Ife (2002), V. Beltran (2010) y M. Moreno (1997). Este último autor, que se ha encargado de editar el códice, ha publicado un gran número de trabajos que en mayor o menor medida atienden a su relación con el Cancionero general y que se citan en la bibliografía final, donde también se incluyen varios estudios de Vicenç Beltran acerca de los cancioneros castellanos relevantes para esta cuestión.

${ }^{19}$ Se trata de: ID0927, "Todas estas confirmaron"; ID0930, "Traygo esperança porque"; ID0931, "Ved el bivo si es razon"; ID0932, "Traygo como veys tristura".

${ }^{20}$ Incluyo en la secuencia los tres textos de paternidad discutida, pero los señalo mediante un signo de interrogación entre paréntesis: ID1113, "De vos me parto quexando"; ID1114, "O muy alto dios de amor"; ID115, "Quien, sin vos, se ha de alegrar" (?); ID1116, "Penoso esta el sentimiento"; ID1117, "Que hare pues me pareçe"; ID1118, "No lloro yo los dolores"; ID0779, "Desconsolado de mí" (?); ID1119, "Pues me mata no miraros"; ID1120, "Quando açierta el desear"; ID1121, "Pensamiento pues mostrays"; ID1122, "Carta pues que vas a ver"; ID1123, "Esta merced cerradura"; ID1124, "Ved que tal es mi bevir"; ID1125, "Discretas damas graciosas" (?); ID1126, "Yo descubro lo encubierto".
} 
monio: es la canción ID1120, "Quando açierta el dessear", recogida en el Cancionero de Poesias Varias (MP2) ${ }^{21}$.

Hay una composición más de Diego López de Haro, obra extensa y de carácter moralizante, que se conserva en un manuscrito único custodiado en la biblioteca de la Real Academia de la Historia, en Madrid, $n^{\circ}$ 9.29.3/5099 (MH4). Se trata del Aviso para cuerdos (ID4281, "Yo a cuerdos hablo y toco"), que ha sido editada y publicada por Erasmo Buceta en el año $1929^{22}$ y, más recientemente, por Ana María Rodado Ruiz ${ }^{23}$.

Este conciso recorrido por algunos hechos de la vida del autor, así como por la obra y las fuentes en las que se conserva, sirve para trazar el perfil de un personaje muy implicado en la vida de la Corte castellana, ya sea desde el punto de vista político y militar o desde el literario, que se relacionó personal o poéticamente con otros autores que figuran en los cancioneros castellanos, que cultivó distintos géneros y abordó varios temas; su labor literaria debió extenderse a lo largo del tiempo, pues aunque su obra no ofrece datos que permitan la datación de los textos, sí se encuentran referencias a que el amor puede causar una muerte prematura, en lo que cabe suponer son poemas de juventud, y frente a ellos están las cartas que dirige al Emperador Carlos V en su madurez. Sobre los últimos años de vida del poeta se conocen muy pocos datos. Se supone que, una vez acabada su misión en Galicia, vuelve a sus posesiones de El Carpio y se ocupa de su hacienda y sus herederos, hasta que muere el 17 de diciembre de $1523^{24}$.

La edición crítica de la obra de un autor como Diego López de Haro tiene ciertas particularidades con respecto a la de otros escritores que vienen dadas, entre otros motivos, por el momento histórico en el que compone, en el que parte de sus poemas se recogen en una fuente impresa y parte en fuentes manuscritas; también el hecho de que sus textos se encuentren en distintos cancioneros, cada uno de ellos organizado de acuerdo con los criterios de su compilador. Puesto que excedería los límites de este artículo detenerme en exponer todas las características y las dificultades que entraña acometer este trabajo de edición, me centraré aquí en la relación entre dos de los cancioneros castellanos más importantes de finales del siglo XV y principios del XVI, el Cancionero general y el Cancionero de la British Library, que son, además, las fuentes principales para la edición y el estudio de la obra de Diego López de Haro.

Como primer paso, tuve que localizar las fuentes en las que se encuentran los testimonios conservados de la producción poética del autor, que son las que he ex-

${ }^{21}$ J. J. Labrador Herráiz, C. A. Zorita y R. A. Difranco (eds.), Cancionero de Poesías Varias. Manuscrito 617 de la Biblioteca Real de Madrid (1986).

${ }^{22}$ E. Buceta (1929a).

${ }^{23}$ A. M. Rodado Ruiz (2009).

${ }^{24}$ E. E. Marcello (1995), p. 128. 
puesto en las páginas anteriores. En el caso de los cancioneros en los que voy a detenerme a continuación, realicé tareas de transcripción de los textos para proceder, posteriormente, a su cotejo. Para la primera edición del Cancionero general (11CG) utilicé el ejemplar custodiado en la Biblioteca Xeral de la Universidad de Santiago de Compostela. Sin embargo, para la edición de 1514 (14CG), puesto que los dos únicos ejemplares conocidos se encuentran en París y Barcelona, tuve que recurrir a una fotocopia del texto conservado en la biblioteca francesa. En cuanto al manuscrito Ms. Add. 10431 (LB1), pude trabajar directamente con él en la Biblioteca Británica mientras disfrutaba de una estancia de investigación en Londres.

Hernando del Castillo dedica, según sus propias palabras, veinte años a reunir los materiales que formarán parte de su Cancionero general, una obra de gran relevancia para el estudio de la poesía del siglo $\mathrm{XV}$, tanto por los textos que recoge (de muchos de ellos es la única fuente con la que se cuenta hoy en día) como por su éxito editorial (se publica hasta nueve veces a lo largo del siglo XVI). Afirma en su famoso "Prólogo":

De veinte años a esta parte, esta natural inclinación me hizo investigar, haver y recolegir de diversas partes y diversos auctores, con la más diligencia que pude, todas las obras que de Juan de Mena acá se escrivieron, o a mi noticia pudieron venir [...]. Donde copilé un cancionero, al parescer mío, assí en generalidad de obras como en precio de ellas, si no muy excelente, a lo menos no malo. ${ }^{25}$

Estas palabras ponen de relieve una de las características que más ha interesado de este cancionero: la diversidad de procedencia de las fuentes utilizadas por el compilador. Además, el modo en que Castillo organiza los materiales de que dispone (en nueve secciones, siguiendo criterios temáticos, genéricos y de autoría) es llamativo por su originalidad y porque denota su voluntad de intervención sobre los textos.

Respecto al primer aspecto, el rastreo de sus fuentes lo relaciona inevitablemente con el Cancionero de la British Library por el número de textos que comparten ${ }^{26}$. En este códice se recogen unos 470 poemas de autores pertenecientes a los reinados de Juan II, Enrique IV y los Reyes Católicos, y alrededor de 200 de ellos los comparte con el cancionero de Hernando del Castillo ${ }^{27}$; sin embargo, pese a que hay una

\footnotetext{
${ }^{25}$ J. González Cuenca (ed.) (2004), p. 189. Además de la excelente edición llevada a cabo por Joaquín González Cuenca, es un referente imprescindible al acercarse al Cancionero general la edición facsímil y el estudio introductorio al cuidado de Antonio Rodríguez Moñino (1958). Para un estado de la cuestión general sobre el cancionero, véase el libro de Estela Pérez Bosch (2009) y el artículo de Vicenç Beltrán (2012).

${ }^{26}$ B. Dutton (1990), p. 89.

${ }^{27}$ B. Ife (2002), p. 62.
} 
relación textual evidente, esta está lejos de resultar clara. Vicenç Beltran afirma que debe existir una fuente común para ambas colectáneas e insiste en la necesidad de llevar a cabo un análisis minucioso de sus estructuras para poder rastrear las fuentes $^{28}$, lo que incide en el segundo aspecto que se había destacado del Cancionero general, la ordenación de los materiales.

En este sentido, Manuel Moreno, a lo largo de los últimos años, ha publicado varios trabajos que aluden a la estructura del manuscrito londinense en su totalidad ${ }^{29} \mathrm{y}$ que detectan en él una voluntad estilística tanto en la ordenación de los materiales como en las variantes que ofrecen los textos ${ }^{30}$. La disposición de los materiales hizo creer a algunos estudiosos que LB1 podría ser un borrador manuscrito destinado a convertirse en texto impreso: pueden distinguirse en él diferentes secciones en función, principalmente, de un criterio de autoría, que se establece en el recto del folio con una rúbrica centrada precediendo al texto y que suele cerrarse al final del verso de un folio, en el que en ocasiones se dejan espacios en blanco ${ }^{31}$. Sin embargo, hasta el momento esta hipótesis no ha resultado demostrable ${ }^{32}$ y de la misma manera tales divisiones podrían reflejar el cambio de fuente por parte del copista ${ }^{33}$.

Lo que se extrae de todo lo expuesto es que en ambas antologías interviene un compilador y esto, sumado a los errores que introduzca el copista, puede dificultar la tarea de identificación de las fuentes. Por otra parte, la aparente uniformidad característica de toda compilación poética no debe hacer olvidar que esta puede estar hecha a partir de distintos materiales y que por tanto no todos los poemas tienen la misma autoridad a la hora de establecer una edición crítica ${ }^{34}$.

Como se ha indicado, LB1 comparte 12 poemas de los 16 de atribución segura a Diego López de Haro con 11CG y uno más, el "Testamento de amores" (ID1114), con 14CG. De esos 13 poemas, 4 son invenciones, que puede suponerse que entraron a formar parte de la compilación a partir de una fuente que recogía los textos de unos determinados festejos cortesanos; los demás aparecen agrupados en un apartado dedicado al autor, en el que se observa, junto al criterio de autoría, uno temático, centrado en torno a una partida y el dolor provocado por la ausencia.

Sin embargo, hay un poema que rompe la coherencia temática de este conjunto de composiciones, el "Debate entre la Razón y el Pensamiento" (ID1121, "Pensamiento pues mostrays"), del que únicamente se recogen las cuatro primeras estrofas, frente a las 31 de que consta en el cancionero de Hernando del Castillo, y, al aparecer introducido por la rúbrica "Otras suyas", desaparece todo rastro de poema dia-

\footnotetext{
${ }^{28}$ V. Beltran (2005), p. 254.

${ }^{29}$ M. Moreno (2000), pp. 1332-1333.

${ }^{30}$ M. Moreno (1999), pp. 38-39.

${ }^{31}$ V. Beltran (1999), p. 29.

${ }^{32}$ M. Moreno (2011), p. 124.

${ }^{33}$ B. Ife (2002), p. 62.

${ }^{34}$ B. Ife (2002), p. 63.
} 
logado. Quizá la explicación de la presencia de estos cuarenta versos se encuentre atendiendo al orden de los poemas en el Cancionero general, pues el único caso de orden idéntico entre las obras de impreso y manuscrito se da en la secuencia ID1121 ("Pensamiento pues mostrays"), que es este "Diálogo entre la Razón y el Pensamiento", ID1122 ("Carta pues que vays a ver"), que es una "Carta de amores", e ID1123 ("Esta merçed cerradura"), poema ligado a la "Carta", pues se presenta como "Cerradura" de esta; pero, mientras que los dos últimos se ajustan perfectamente al tema de la partida, en LB1 el debate parece sobrar. Es posible, por tanto, conjeturar que, en la fuente de la que disponía el copista, la "Carta" (ID1122) fuese precedida del "Diálogo" (ID1121), que empezó a copiar por error, tarea que abandona después de la cuarta estrofa, al darse cuenta del equívoco, o tal vez lo copiase intencionadamente con una finalidad tipográfica, para que la obra de Diego López de Haro ocupase hasta el final del recto de la página.

En cualquier caso, la coincidencia de esta secuencia de tres poemas en ambos cancioneros podría apuntar a una fuente común, aunque las diferencias en la rúbrica del "Diálogo" (ID1121) y el hecho de que solo se copien cuatro estrofas parecen anular cualquier dependencia directa de un cancionero hacia otro. Desde luego, sería imposible que LB1 fuese la fuente de 11CG, pero hay otra característica de esta secuencia que parece demostrar que tampoco la antología de Hernando del Castillo pudo ser la fuente del códice londinense: tanto el "Diálogo" (ID1121) como la "Carta" (ID1122) utilizan la copla de pie quebrado, forma métrica frecuente en la producción de Diego López de Haro. Sin embargo, en la versión del Cancionero de la British Library, tres de las cuatro estrofas del "Diálogo" (ID1121) y dos de las ocho de la "Carta" (ID1122) eliminan el pie quebrado rellenando el verso con expresiones vacías de significado de forma que lo convierten en octosílabo. Que esto ocurra en dos poemas, que además aparecen en el mismo orden en dos cancioneros distintos, puede ser prueba de que ambos proceden de la misma fuente. En cualquier caso, no parece que sea una costumbre del copista de LB1 rellenar los versos y eliminar el pie quebrado, al menos yo no he encontrado otro caso en el códice, por lo que podría ser un indicio de que tampoco el cancionero manuscrito copió del impreso.

Otro de los aspectos que ha preocupado al respecto de la relación entre estos cancioneros ha sido el de la datación, pero si se tiene en cuenta que no parece posible establecer una dependencia directa de uno sobre otro, es también muy difícil determinar cuál precede a cuál. Atendiendo únicamente a la obra de Diego López de Haro, hay que recordar que el "Testamento de amores" (ID 1114, "O muy alto dios de amor") aparece por primera vez en el Cancionero general en la segunda edición, la de 1514. Este poema es el único que comparten LB1 y 14CG que no aparece en 11CG, aunque las diferencias textuales entre impreso y manuscrito son muy notables, pues afectan incluso al número de versos y al orden de las estrofas. Aunque este texto no figurase en la primera edición del impreso, es muy probable que circulase de forma oral o escrita, pues se establece explícitamente como modelo para el "Testamento" de Garci Sánchez de Badajoz, texto que sí se recoge en 11CG. 
Es decir, que en el caso de nuestro autor LB1 tenga más textos en común con 14CG que con 11CG no significa ni que derive de él ni que haya utilizado fuentes posteriores a 1511. Indudablemente el "Testamento de amores" de Diego López de Haro se había compuesto antes de que Hernando del Castillo publicase su cancionero y era ampliamente conocido, por lo que su inclusión en $14 \mathrm{CG}$ y LB1 y no en $11 \mathrm{CG}$ no puede ser, en ningún caso, un criterio de datación para el manuscrito londinense.

Por otra parte, la alusión de Garci Sánchez al "Testamento de amores" no solo es útil a la hora de establecer una cronología para el poema, sino que puede ayudar en la toma de decisiones sobre el orden correcto de las estrofas, puesto que, además de que este tipo de testamentos tienen, en general, una estructura común ${ }^{35}$, el suyo tiene "la misma forma y tenor" que el de Diego López de Haro ${ }^{36}$.

Estos ejemplos ponen de relieve la compleja relación existente entre estos cancioneros, así como la necesidad de seguir profundizando en ella a través de estudios, parciales o de conjunto, para llegar a comprender mejor aspectos como las técnicas de composición o la procedencia de los materiales. En este sentido, las ediciones de la obra de los poetas que figuran entre sus páginas pueden ayudar a arrojar alguna luz sobre estas cuestiones, al tiempo que se benefician de los progresos que se van logrando en este ámbito y el caso de Diego López de Haro es una muestra de ello.

\section{Obras citadas}

ALVAR, Carlos: "LB1 y otros cancioneros castellanos", en Lyrique romane médiévale: la tradition des chansonniers. Actes du Colloque de Liége (1989), Liége, Universitè de Liége, 1991, pp. 469-500.

BELTRAN, Vicenç: "Tipología y génesis de los cancioneros. El Cancionero de Juan del Encina y los cancionero de autor", en J. Gujarro Ceballos (ed.), Humanismo y literatura en tiempos de Juan del Encina, Salamanca, Ediciones Universidad de Salamanca (Acta Salmanticensia. Estudios filológicos, 271), 1999, pp. 27-53.

: "Ordenado y corregido por la mejor manera y diligencia. Hernando del Castillo, editor", en P. Botta (ed.), Filologia dei testi a stampa (area iberica), Modena, Mucchi Editore, 2005, pp. 241-256.

: "El Cancionero general (Valencia, 1511) y el Cancionero de la Biblioteca Británica", en Da Papa Borgia a Borgia Papa. Letteratura, linga e traduzione a Valencia, Lecce, Pensa, 2010, pp. 121-150.

: "Quinientos años de Cancionero General", en Marta Haro, Rafael Beltrán, José Luis Canet y Héctor H. Gassó (eds.), Estudios sobre el Cancionero

\footnotetext{
${ }^{35}$ A. Chas Aguión (2006), pp. 69-77.

${ }^{36}$ C. Parrilla (2001), pp. 49-50.
} 
General (Valencia, 1511): Poesía, Manuscrito e Imprenta, Valencia, Universitat de València, 2012, pp. 15-35.

BotTA, Patrizia: "Las fiestas de Zaragoza y las relaciones entre LB1 y 16RE", con un Apéndice de Juan Carlos Conde, Incipit, XXII (2002), pp. 3-51.

: "La rubricación cancioneril de las letras de justadores", en Pedro M.

Piñero Ramírez (ed.), Dejar hablar a los textos. Homenaje a Francisco Márquez Villanueva, Sevilla, Universidad, 2005, pp. 173-192.

BUCETA, Erasmo: "Aviso para cuerdos", Revue Hispanique, 76 (1929a), pp.321345.

: "Contribución al estudio de la diplomacia de los Reyes Católicos", Anuario de Historia del Derecho Español, 6 (1929b), pp. 145-196.

: "Tres cartas de Don Diego López de Haro al Emperador", Boletín de la Real Academia Española, 17 (1930), pp. 363-395.

: "Cartel de desafío", Revue Hispanique, 81-1 (1933), pp. 456-474.

CHAS AGUión, Antonio: "Los testamentos en la poesía de cancionero", Revista de poética medieval, 16 (2006), pp. 53-78.

CONDE, Juan Carlos: "LB1: hacia la historia del códice", en J. C. Conde y V. Infantes, De cancioneros manuscritos y poesía impresa: estudios bibliográficos y literarios sobre lírica castellana del siglo XV, Madrid, Arco Libros, 2007 [2002], pp. 55-67.

CUESTA TORRE, María Luzdivina: "Las invenciones de don Diego López de Haro", en A. Deyermond (ed.), Proceedings of the Tenth Colloquium, Londres, Department of Hispanic Studies, Queen Mary and Westfield College, 2000, pp. 6584.

DE NIGRIS, Carla: "Giochi verbali e nomi di donna nelle invenciones", en Andrea Baldissera y Giuseppe Mazzocchi (eds.), I Canzonieri di Lucrezia. Los Cancioneros de Lucrecia (Ferrara, 7-9 ottobre 2002), Padova, Unipress, 2005, pp. 281-300.

DEYERMOND, Alan: "La micropoética de las invenciones", en Juan Casas Rigall (ed.), Iberia cantat: estudios sobre la poesía hispánica medieval, Santiago de Compostela, Universidad, 2002, pp. 397-418.

DutTON, Brian: "El desarrollo del Cancionero general de 1511", en E. Rodríguez Cepeda (ed.) con la colaboración de S. G. Armistead, Actas del Congreso Romancero-Cancionero, UCLA (1984), Madrid, Purrúa Turanzas, 1990, pp. 81-96.

García OrO, José: Galicia en los siglos XIV y XV, Madrid, CSIC, 1987.

GONZÁLEZ CuENCA, Joaquín (ed.): Cancionero general, Madrid, Castalia (Nueva Biblioteca de Erudición y Crítica, 26), 5 vols, 2004.

GORNALL, John: "Invenciones and their Authors at Zaragoza", La corónica, 28.2 (2000), pp. 91-100.

: The invenciones of the British Library Cancionero, Londres, Department of Hispanic Studies, Queen Mary, University of London (Papers of the Medieval Hispanic Research Seminar, 41), 2003a. 
: "11CG and LB1: a Hundred of Invenciones but How Many Tournaments?", en Alan Deyermond y Jane Whetnall (eds.), Proceedings of the Twelfth Colloquium, London, Department of Hispanic Studies, Queen Mary, University of London, (Papers of the Medieval Hispanic Research Seminar, 35), 2003b, pp. 111-116.

IFE, Barry: "Dutton LB1 and the sources of Garci Sánchez de Badajoz", en S. Boyd y J. Richardson (eds.), Spanish Poetry of the Golden Age: Papers of a Colloquium Held at University College Cork, Manchester, Department of Spanish and Portuguese Studies, 2002, p. 59-84.

JONES, Royston Oscar: "Encina y el Cancionero del British Museum", Hispanófila, 11, (1961), pp. 1-21.

KENNEDY, Kirstin: "Inventing the Wheel: Diego López de Haro and his 'invenciones"”, Bulletin of Hispanic Studies, 79, 2 (2002), pp.159-174.

LABRADOr HerráIz, José, Zorita, C. Ángel y Difranco, Ralph A. (eds.): Cancionero de Poesías Varias. Manuscrito 617 de la Biblioteca Real de Madrid, Anejos del Anuario de Filología Española. El Crotalón, 1986.

LEDDA, Giuseppina: La letteratura emblematica, Pisa, Università, 1970.

LÓPEZ FERREIRO, Antonio: Galicia en el último tercio del siglo $X V$, Vigo, Editorial Compostela, 1968.

MACPHERSON, Ian: "Fray Iñigo de Mendoza, Francisco Delicado y dos enigmas salomónicos", en José Manuel Lucía Megías (ed.), Actas del VI Congreso de la AHLM, Alcalá de Henares, Universidad de Alcalá de Henares, Servicio de Publicaciones, 1997a, I, pp.39-56.

: "Text, Context and Subtext: Five invenciones of the Cancionero General and the Ponferrada Affair of 1485", en Ian Macpherson y Ralph Penny (eds.), The medieval mind: Hispanic studies in Honour of Alan Deyermond, London, Tamesis, 1997b, pp. 259-274

: The 'Invenciones y letras' of the 'Cancionero general', Londres, Department of Hispanic Studies, Queen Mary and Westfield College (Papers of the Medieval Hispanic Research Seminar, 9), 1998.

: "The game of Courtly Love: Letra, divisa and invenciones at the court of the Catholic Monarchs", en E. Michael Gerli y Julian Weiss (eds.), Poetry at Court in Trastamaran Spain, Tempe, Arizona, Medieval \& Reinassance Texts \& Studies, 1998a, pp. 95-110.

: "Manteniendo la tela: el erotismo del vocabulario caballeresco-textil en la época de los Reyes Católicos", en Ralph Penny (ed.), Actas del I Congreso Anglo-hispano, Madrid, Castalia, 1998b, pp.25-36.

MAZZOCCHI, Giuseppe: "Un manoscritto milanese (Biblioteca Ambrosiana S.P.II.100) e l'ispanismo del Bembo", en Cancionero spagnoli a Milano, I, Firenze, La Nuova Italia, 1989, pp. 67-100.

MARCELlo, Elena Elisabetta: "Diego López de Haro, poeta cancioneril. Profilo storico-biográfico", Il Confronto Letterario. Quaderni del Dipartamento di Lin- 
gue e Letterature Straniere Moderne dell'Università di Pavia e del Dipartimento di Lingüistica e Letterature Comparate dell'Università di Bergamo, 23 (1995), pp. 105-129.

MÁRQUeZ VILlANUEVA, Francisco: Investigaciones sobre Juan Álvarez Gato. Contribución al conocimiento de la literatura castellana del siglo XV, Madrid, Real Academia Española, 1960.

MorenO, Manuel: "Sobre la relación de $L B 1$ con $11 C G$ y $14 C G$ ", en J. M. Lucía Megías (ed.), Actas del VI Congreso Internacional de la Asociación Hispánica de Literatura Medieval, Alcalá de Henares, Universidad de Alcalá de Henares, 1997, vol. II, pp. 1069-1083.

: "Las variantes en el Ms. Add. 10431 de la British Library (LB1)", en S.

Fortuño Llorens y T. Martínez Romero (eds.), AHLM. Actes del VII Congrés, Castelló de la Plana, Publicacions de la Universitat Jaume I, 1999, vol. 3, pp. 3748.

: "Una nueva edición de LB1", en M. Freixas, S. Iriso y L. Fernández (eds.), Actas del VIII Congreso Internacional de la Asociación Hispánica de Literatura Medieval, Santander, Consejería de Cultura del Gobierno de Cantabria Año Jubilar Lebaniego - Asociación Hispánica de Literatura Medieval, 2000, vol. 2, pp. 1327-1339.

: "El dulce placer de significar agudamente lo que se quiere decir: sobre una invención de LB1", Bulletin of Hispanic Studies (Liverpool), 78 (2001a), pp. 465-487.

: "Transmisión y estructura en $L B 1$. Pliegos sueltos y unica", P. Botta, C. Parrilla e I. Pérez Pascual (eds.), en Canzonieri iberici, Noia, Università di Padova - Toxosoutos - Universidade da Coruña, vol. 2, 2001b, pp. 287-307.

: "La imprenta en el cancionero manuscrito de Rennert (LB1)", J. L.

Martos (coord.), en Del impreso al manuscrito en los cancioneros, Alcalá de Henares, Instituto de Estudios Cervantinos, 2011, pp. 113-170.

PARRILlA, Carmen: El cancionero del comerciante de A Coruña, Noia, Toxosoutos (Biblioteca Filológica, 9), 2001.

PÉREZ BosCH, Estela: Los valencianos del Cancionero General: estudio de sus poesías, Parnaseo, Valencia, Publicaciones de la Universitat de València, 2009.

RENNERT, Hugo Albert: "Der Spanische Cancionero des Brit. Museums (Ms. Add. 10431). Mit Einleitung und Anmerkungen zum erstenmal herausgegeben", Romanische Forschungen, X, (1899), pp. 1-176.

RICO, Francisco: "Un 'penacho de penas': sobre tres invenciones del Cancionero General", Romanistisches Jahrbuch, 17 (1966), pp. 274-284.

RoDADO RUIZ, Ana María: "«Yo a cuerdos hablo y toco»: el «Aviso para cuerdos» de Diego López de Haro", Cancionero General, 7 (2009), pp. 95-133.

RODRíGUEZ MOÑINO, Antonio (ed.): Cancionero general (facsímil), Madrid, Real Academia Española, 1958. 
SÁNCHEZ PÉREZ, Aquilino: La literatura emblemática española (siglos XVI y XVII), Madrid, Sociedad General Española de Librería, 1977. 